\title{
EFFECT OF SURFACE MODIFICATION AND GEOMETRY ON WATER DROPLET EROSION PERFORMANCE
}

\author{
Abdullahi K. Gujba ${ }^{1}$, Auezhan Amanov ${ }^{2}$, Mamoun Medraj ${ }^{1, *}$ \\ ${ }^{1}$ Department of Mechanical, Industrial and Aerospace Engineering, Concordia University, Montreal, Canada \\ ${ }^{2}$ Department of Mechanical Engineering, Sun Moon University, Asan, South Korea \\ *mmedraj@encs.concordia.ca
}

\begin{abstract}
This work studies the influence of surface modification and specimen geometry on the water droplet erosion (WDE) performance of Ti-6Al-4V. Ultrasonic nanocrystalline surface modification (UNSM) was employed and two different specimen geometries (flat and airfoil) were explored. The airfoil geometry is similar to the leading edge of compressor blades in gas turbines. UNSM condition had deep levels of induced compressive residual stresses compared to the untreated condition. Electron backscatter diffraction (EBSD) results show that UNSM treatment refined the microstructure which translates to enhanced microhardness compared with the untreated (As-Machined (As-M)) condition. The WDE performance tests were conducted in a rotating disc rig in accordance with ASTM G73 standard. WDE results showed that the T-shaped flat UNSM samples had enhanced WDE performance at speeds of 250 and $300 \mathrm{~m} / \mathrm{s}$ compared to the As-M ones. WDE performance of the UNSM airfoil without edge treatment $(0.5 \mathrm{~mm}$ from the edge $)$ mitigated the erosion damage especially at the advanced stages compared to As-M airfoil. This is due to the fact that compressive residual stresses are through the thickness of the airfoil which suppresses crack initiation and propagation.
\end{abstract}

Keywords-UNSM; Erosion; Microhardness; Microstruture; Speed;

\section{INTRODUCTION}

WDE is the progressive loss of material from a solid surface due to accumulated impacts by water droplets [1]. WDE is a complex phenomenon that existed for considerable long period of time and the reason for this is the number of parameters involved and their variations during the erosion process. These parameters include: impact speed, impact angle, droplet size, droplet density, frequency of impacts, liquid film formation, mechanical properties and conditions of the target material. More information on the influence of WDE parameters such as droplet size, impact speed, impact angle have been reported in [2]. WDE damage is predominantly caused by two main factors; (1) the high pressure exerted by the water droplet on the impacted area of the solid surface and (2) the radial liquid flow (lateral jetting) along the surface at high speed, which occurs after the initial droplet pressure lessens [3]. Figure 1 shows a typical droplet impact and its radial outflow (lateral jetting).

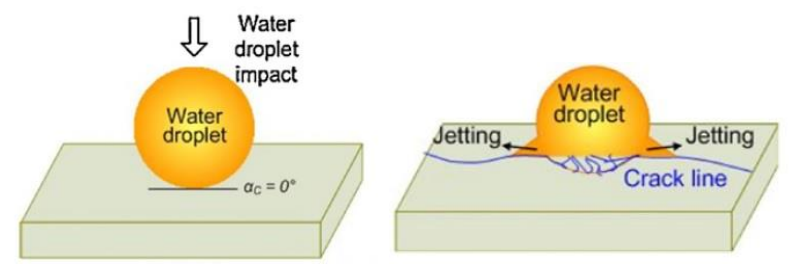

Figure 1: Water droplet impact and the radial outflow (lateral jetting) [4].

Understanding and mitigating this undesirable phenomenon is paramount. The two most effective means of mitigating water droplet erosion damage are to minimize the main factors causing the erosion damage or to enhance the surface and mechanical properties of the materials used in applications where WDE is encountered. Also, understanding the damage mechanisms during WDE is important in order to find lasting solutions. For instance, existing literature [5,6] suggests that WDE is likened to fatigue-like damage due to the continuous liquid impacts in a cyclic fashion. The crack initiation and propagation have been found to significantly influence WDE behaviour similar to fatigue. It is well known that induced compressive residual stresses from mechanical surface treatments retard crack initiation and further propagation and improves fatigue life. Hence, mechanical surface treatments are expected to enhance WDE performance as well. Recently, surface treatments known to enhance fatigue resistance such as deep rolling (DR) [6], and laser shock peening (LSP) [7] have been explored. This work explores Ultrasonic nanocrystalline surface modification which is relatively a new surface modification technique that uses ultrasonic vibration energy which converts harmonic oscillations of an excited body into resonant impulses of high frequency. The generated energy from these oscillations are used to impact the work piece at high frequency of up to 20 $\mathrm{kHz}$. Typical impacts on the work piece surface ranges from 20,000 to 40,000 shots per square millimeter [8]. The high frequency striking leads to severe plastic deformation of the 
surface, thereby introducing high dislocations density. Thus, nanocrystalline surface layer is formed beneath the specimen surface. Modifying the top surface and in-depth of the work piece in turn, improves the mechanical properties. The strengthening effect is due to the plastic strain and refined microstructure. In the proposed work, two different specimen geometries (T-shaped flat and airfoil) were UNSM treated. Similar approach was adopted for the T-shaped flat as in previous studies in [9]. However, the airfoil specimens were treated using two approaches. More on the UNSM processing, sample characterizations and WDE tests are detailed in the following section.

\section{EXPERIMENTAL PROCEDURE}

\section{A. Material and geometry}

In the present study, Ti-6Al-4V (ASTM B265, Grade 5) alloy, used for compressor blades in gas turbines, is studied. The starting microstructure of the Ti-6Al-4V alloy contains $\alpha-$ and $\beta$-phases. T-shaped and airfoil samples were machined to fit the WDE testing rig as shown in Figure 2.

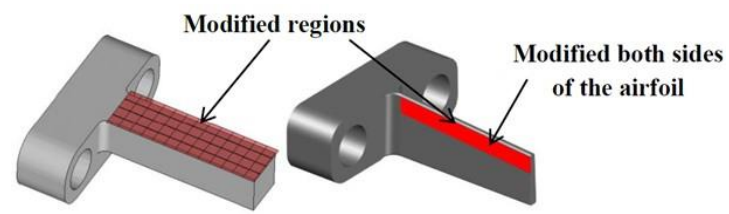

Figure 2: Typical machined and treated T-shape (left) and airfoil (right) geometries.

\section{B. UNSM treatment and characterization}

\section{1) UNSM processing}

The as-machined (As-M) samples (T-shaped and airfoil) surfaces were modified using UNSM apparatus at Sun Moon University, South Korea. The modified surfaces are indicated in Figure 2. The UNSM process parameters are summarized in Table I. It is worth noting that the airfoil sample was treated on both sides in order to avoid sample distortion due to tensile stresses. The airfoil specimens were treated using two approaches. First, treatment included the leading edge of the specimen and the second; treatment did not include the leading edge and stooped $0.5 \mathrm{~mm}$ away from it. For simplicity, untreated and treated specimens are referred to as As-M and UNSM specimens, respectively in this paper.

Table I: UNSM processing parameters for Ti-6Al-4V

\begin{tabular}{lc}
\hline Ball material & Tungsten carbide (WC) \\
\hline Ball tip (mm) & 2.38 \\
\hline Static load $(\mathrm{N})$ & 30 \\
\hline Frequency $(\mathrm{kHz})$ & 20 \\
Interval $(\mathrm{mm})$ & 0.01 \\
Amplitude $(\mathrm{um})$ & 24 \\
Speed $(\mathrm{mm} / \mathrm{min})$ & 2000 \\
\hline
\end{tabular}

\section{2) Characterization}

Mitutoyo SJ-210 portable surface roughness tester was used to measure the surface roughness $\left(\mathrm{R}_{\mathrm{a}}\right)$ before and after UNSM treatment. An average of 5-7 readings was taken across the specimen surfaces.

Residual stresses were measured in two different directions i.e. transverse $\left(0^{\circ}\right)$ and scanning $\left(90^{\circ}\right)$. Crystallographic plane of $\{213\}$ and diffraction angle $\left(2 \theta=142^{\circ}\right)$ obtained by $\mathrm{Cu} \mathrm{K} \alpha$ radiation were used. For quantifying the residual stress values with respect to depth, surface layers were gradually removed by electropolishing.

Microhardness measurements were carried out on the top surface and cross-section of all treated and untreated specimens. A direct load of 50 gram-force (gf) was applied and a dwell time of 15 seconds was used.

To observe any surface features such as microdimples, the as-treated top surface was observed under SEM (S-3400N, Hitachi). More surface microstructural features such as grain refinement were observed using electron backscatter diffraction (EBSD).

\section{WDE testing and characterization}

A rotating disc rig available at Concordia University was used for studying the WDE performance. Details about this unique erosion rig has been reported in [10]. The test was conducted in accordance with the ASTM G73 standard [11]. In this rig, the reference untreated and UNSM treated coupons were fixed at diametrically opposite ends of the rotating disc as demonstrated in [10]. It is worth noting that the surface roughness of both treated and untreated specimens was similar prior to erosion testing. Two types of nozzles of droplet size of $463 \mu \mathrm{m}$ were used depending on the geometry to be tested. A shower head nozzle (13 orifices) was used for testing the airfoil specimen, whereas a single streak nozzle was used for testing the T-shaped flat specimen. Typical WDE testing parameters are summarized in Table II. The setup enabled the droplets to impact the samples at $90^{\circ}$ in a repetitive fashion. The impact angle of $90^{\circ}$ causes the most severe water erosion damage. The erosion exposure time depended on the impact speed used.

Table II: WDE test parameters used in the present work

\begin{tabular}{c|cc}
\hline WDE parameters & Flat specimen & Airfoil specimen \\
\hline Impact speed (m/s) & $250,300,350$ & 300,350 \\
Flow rate (liter/min) & 0.05 & 0.15 \\
Nozzle head type & Single streak & Shower head \\
\hline
\end{tabular}

During the WDE tests, experiments were halted at certain intervals and specimens were weighed using a balance having $\pm 0.2 \mathrm{mg}$ accuracy. Typical erosion curves such as cumulative mass loss versus number of impingements and the instantaneous erosion rate (inst. ER) versus number of impingements were plotted. To observe the erosion rate as the erosion test progressed, the instantaneous erosion rate (inst. ER) which is the slope between two consecutive points on the erosion-time graphs were plotted. To understand how the erosion process evolved and progressed, images were taken using a standard stereo optical microscope at the intervals during which mass loss was measured. 


\section{RESULTS AND DISCUSSION}

\section{A. Effect of UNSM on surface and in-depth characteristics}

The effectiveness of UNSM and its associate properties have been established and reported. This process has been considered as an effective and economically viable method for producing nano-corrugated and nanostructured [8] surface layers. This is due to the accompanied grain refinement. Properties and microstructure of the treated surface layers can be controlled by careful selection of process parameters such as static load, amplitude, ball tip diameter and interval.

$R_{a}$ which is the average surface roughness $\left(R_{a}\right)$ values before and after UNSM treatments were obtained. It should be noted that before UNSM treatment both had $R_{a}$ values of $0.71 \pm 0.06 \mu \mathrm{m}$. After modifying the surface, $R_{a}$ reduced to $0.26 \pm 0.02 \mu \mathrm{m}$ (about $63 \%$ reduction). It is important to note that a relatively uniform roughness was observed across the treated surface. This observation is also in accord with the findings of [8]. For comparative studies, the surface roughness of treated and untreated specimens must be made comparable [8]. In this study, the untreated specimens were further polished to a comparable surface roughness similar to the UNSM specimens.

UNSM as a mechanical surface treatment that plastically deforms the material surface induces large and deep compressive residual stresses into the material. In this study, the top surface and in-depth compressive residual stresses were quantified in the scanning and transverse directions. Surface of untreated condition showed $-607 \pm 9$ and $-490 \pm 19 \mathrm{MPa}$ in the scanning and transverse directions, respectively. The modified surface showed $-1582 \pm 28$ and $-863 \pm 18 \mathrm{MPa}$ in the scanning and transverse directions, respectively. The high stresses are attributed to the local plastic deformation and induced strain hardening during UNSM processing. This finding is in accord with observation elsewhere on UNSM-treated Ti-6Al-4V [8]. The in-depth profile has been reported by the current authors in [9]. More microstructural features such as the formation of surface microdimples after UNSM has been discussed in [9]. In this paper, EBSD analysis was conducted and the average grain sizes before and after UNSM were observed. Figures $3 a$ and $b$ show that EBSD images and average grain size distribution for the untreated and treated conditions. The average grain size before and after UNSM is 20.1 and $12.4 \mu \mathrm{m}$, respectively. In other words, there was a $38 \%$ decrease in the average grain size after UNSM processing. It is important to note that the grain size could be reduced further by increasing the striking number and/or amplitude. However, over processing may deteriorate the desired properties.

The microhardness values of the untreated and UNSM treated conditions were also evaluated. The UNSM showed enhanced microhardness as compared with the untreated condition. The top surface microhardness values were $331 \mathrm{HV}$ and $379 \mathrm{HV}$ for untreated and UNSM conditions, respectively. Based on the parameters used, there was a $15 \%$ increase in microhardness after UNSM.
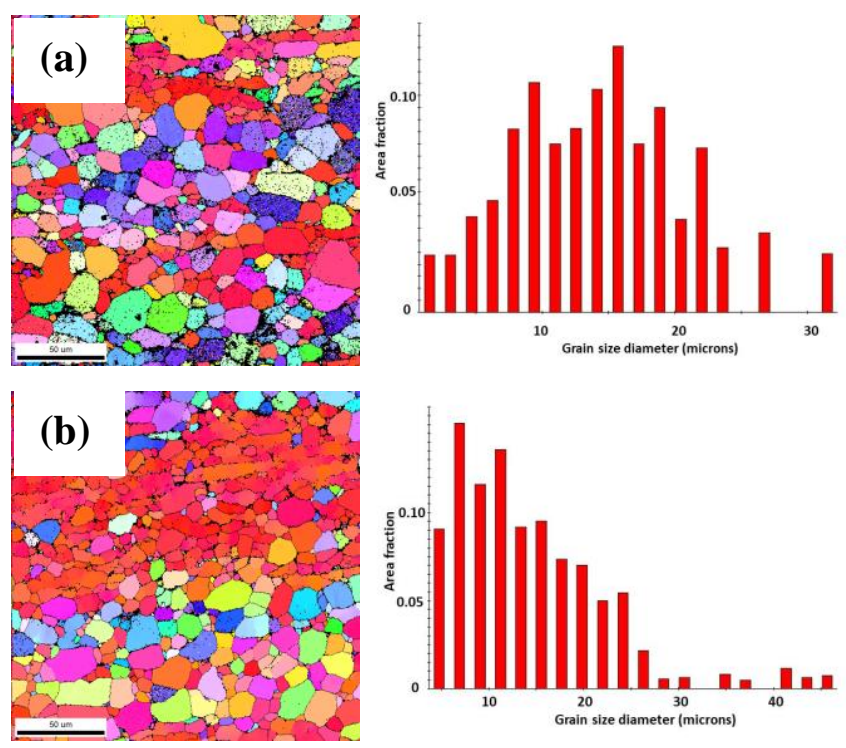

Figure 3: EBSD images of (a) untreated and (b) UNSM treated conditions.

\section{B. Water droplet erosion performance testing}

Prior to the WDE tests, the average $R_{a}$ for the untreated and UNSM conditions were approximately $0.25 \pm 0.03 \mu \mathrm{m}$ and $0.26 \pm 0.02 \mu \mathrm{m}$, respectively. This is to eliminate the effect of surface roughness because surface defects or imperfections such as scratches affect the WDE behaviour of materials. Impact speed was varied while keeping other parameters constant (Table II). For the T-shaped flat specimens, impact speeds of 250, 300 and $350 \mathrm{~m} / \mathrm{s}$ were selected. The cumulative mass loss versus the number of impingements (droplets) graphs were plotted. The number of impingement was determined using Equation 1.

$$
\boldsymbol{N}_{\text {imp }}=\boldsymbol{R} \times \boldsymbol{E}_{\mathrm{t}} \times \boldsymbol{N}_{\text {droplets }}
$$

Where $N_{i m p}$ is the number of impingement (droplets), $R$ is the rotational speed (rpm), $E_{t}$ is the erosion exposure time (minutes) and $N_{\text {droplets }}$ is the number of droplets hitting the sample per revolution. For the flat specimen geometry in this work, $N_{\text {droplets }}$ is 6 as reported in [10]. For the airfoil specimen, impact speeds of 300 and $350 \mathrm{~m} / \mathrm{s}$ were used. Speed less than $300 \mathrm{~m} / \mathrm{s}$ for airfoil geometry would mean testing for prolonged erosion time without significant mass loss. Contrary to the flat specimen geometry, there is a challenge of quantifying the number of droplets hitting the airfoil specimen. This is due to the shower head nozzle used during testing and the small impact area. Hence, graphs of cumulative mass loss versus number of cycles were plotted. The number of cycles is simply the rotational speed (rpm) multiplied by the erosion exposure time (minutes).

1) WDE performance of UNSM vs. As-M T-shaped specimen conditions

Figures 4a-c show the cumulative mass loss versus number of impingements graphs for the T-shaped flat specimens. Figure 4a shows that similar WDE performance was observed 
at $350 \mathrm{~m} / \mathrm{s}$ for UNSM and As-M conditions. In other words, both conditions showed similar erosion trend in terms of initial mass loss and subsequent erosion stages. This is attributed to the severity of the test conditions. In this work, the UNSM treatment showed little or no beneficial effect in enhancing WDE performance at such high impact speed. For instance, the water hammer pressure which is the induced pressure exerted by the "arrested" liquid droplet on the solid surface is significantly high. According to Heymann [12], this pressure can be considerably higher than the yield strength of test materials especially at high impact speeds. Equation 2 provides a reasonable estimation of the critical impact pressure with the condition that Mach number $(M i)$ is greater than 0.2 as reported in [12].

$$
P=\rho C V\left(2+\frac{2 K-1) V}{C}\right)
$$

Where $P$ is the pressure, $\rho$ is the density of the liquid (1000 $\left.\mathrm{kg} / \mathrm{m}^{3}\right), C$ is the acoustic velocity of the liquid $(1500 \mathrm{~m} / \mathrm{s}-$ for water), $V$ is the impact velocity $(\mathrm{m} / \mathrm{s})$ and $K=2$ for water. Based on Equation 2, one can see that the impact pressure is proportional to the impact speed and at higher speeds the pressure induces stress levels that exceed the yield strength of the material. Also, the relationship between pressure distributions and $M i$ ranges has been established in [13]. They [13] reported that the difference in pressure at the center and edge of the droplet is minimized for low $M i$ range between 0.1 and 0.4 . For high $M i(>0.4)$, the edge pressure is 3 times that of the center when jetting starts and this significantly influences the initiation period. In this work, impact speeds equal to or greater than $300 \mathrm{~m} / \mathrm{s}$ will satisfy the assumption of [12] and relationship established by [13]. This explanation is in accord with the claims made by Lesser and Field [14] that the response of liquid droplet changes corresponding to changes in impact speed. They [14] stated that "if the impact speed is sufficiently low for a given liquid, distinct shocks and high-speed jetting would not be expected" and vice versa. By this claim, at speeds equal to greater than $300 \mathrm{~m} / \mathrm{s}$, the WDE performance will be influenced largely by stress waves and their interactions, and lateral jetting leading to significant loss of material. Figure 5 shows the influence of impact speed on the crater behavior. It can be seen that at higher speeds $(\geq$ $300 \mathrm{~m} / \mathrm{s}$ ) the lateral jetting is more profound as compared to the evenly distributed jetting effect at lower speed $(250 \mathrm{~m} / \mathrm{s})$. This explanation is in accord with the findings in [10]. At $300 \mathrm{~m} / \mathrm{s}$ (Figure 4b), UNSM showed improved WDE performance as compared with the As-M condition. At $250 \mathrm{~m} / \mathrm{s}$ (Figure 4c), UNSM condition showed the most enhanced WDE performance compared to the As-M condition. The enhanced WDE performance observed in this study at speed 250 and $300 \mathrm{~m} / \mathrm{s}$ are mainly attributed to the increased microhardness and modified microstructure. Heymann [5,15] stated that microhardness is a good and reliable material property used in assessing the resistance of materials to erosion damage. Reports $[5,16]$ have shown that the erosion resistance varies with $2^{\text {nd }}$ to $3^{\text {rd }}$ power of Vickers hardness number. More so, refined microstructure or reduction in grain size has also been associated with erosion resistance of materials [16]. More discussions have been reported by the current authors in [9].
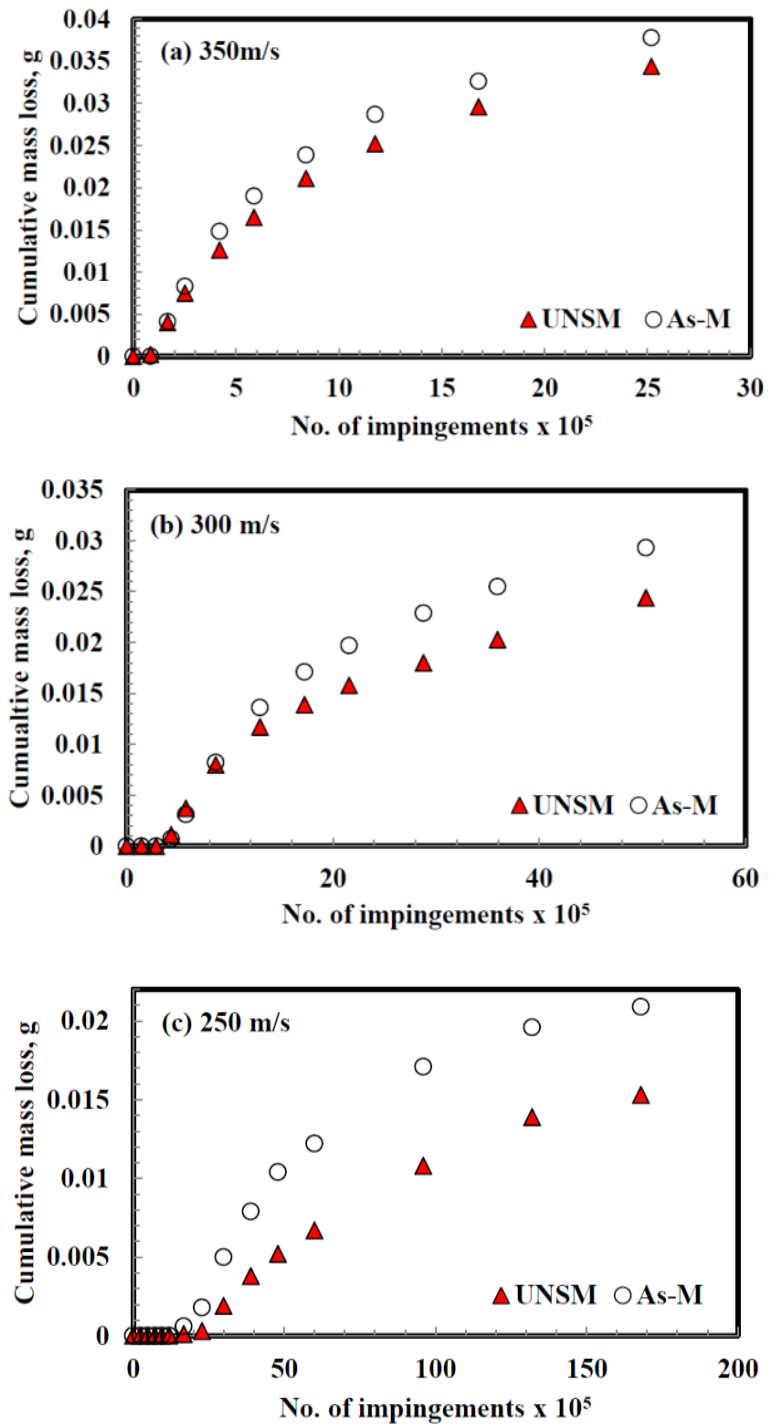

Figure 4: WDE curves of As-M versus UNSM flat samples at different impact speeds.

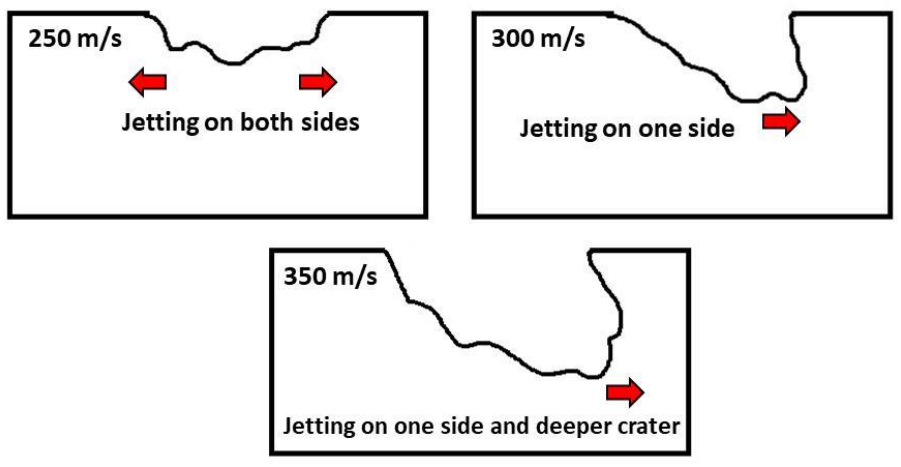

Figure 5: Influence of impact speed on the crater behavior. 
2) WDE performance of UNSM vs. As-M Airfoil specimen conditions

Similar to the WDE investigations on the flat T-shaped specimen, As-M and UNSM-treated airfoil conditions were studied. Figure 6 a shows that at $350 \mathrm{~m} / \mathrm{s}$, both conditions had the same initial mass losses but after additional number of cycles, the UNSM showed more mass loss as compared with the As-M condition. This can be attributed to the severity of the test which induced high stress levels. Also, due to the work hardened surfaces on both sides of the airfoil, the material is most likely to fail in a brittle manner, allowing cracks to propagate easily and chip out large chunk of material. This observed trend is also shown in Figure 7a where the UNSM condition showed higher inst. ER $\mathrm{max}_{\max }$ than the As-M condition. Figure $6 \mathrm{~b}$ shows that at $300 \mathrm{~m} / \mathrm{s}$, both conditions showed initial mass losses but the UNSM condition further lost material with additional cycles. Interestingly, the UNSM started showing better WDE performance than the As-M condition. This is demonstrated clearly in the region A of Figure $7 \mathrm{~b}$ where the UNSM treatment mitigated further erosion damage. Similar tests were carried out using $300 \mathrm{~m} / \mathrm{s}$ and similar trends were observed. Hence, it can be hypothesized that the induced compressive residual stresses might have arrested crack propagations similar to the crack arrest in stress corrosion cracking (SCC) tests [17].
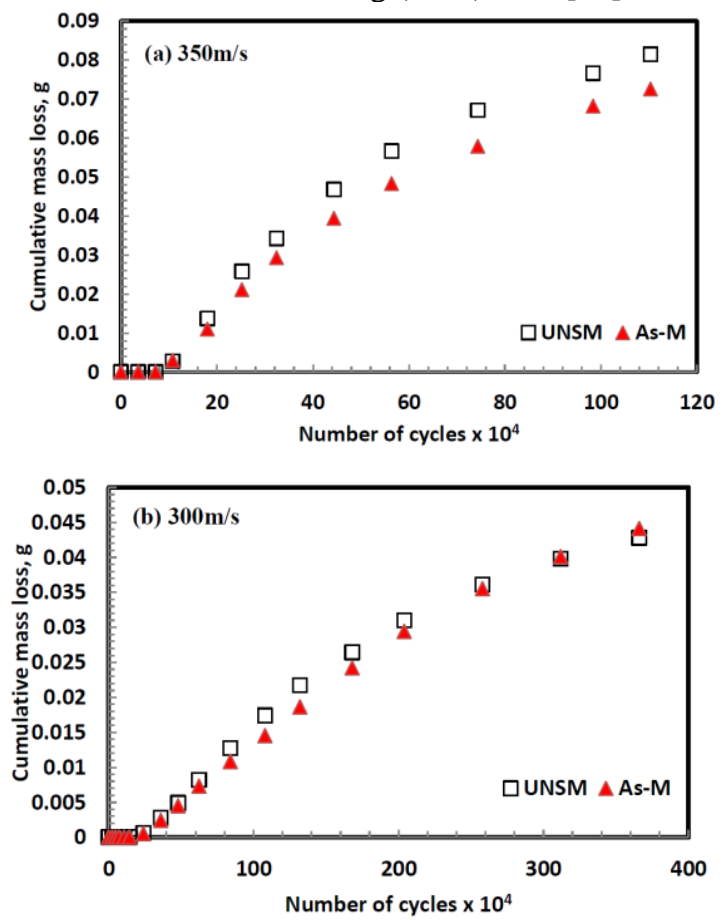

Figure 6: WDE curves of As-M and UNSM airfoil samples at different impact speeds [9].
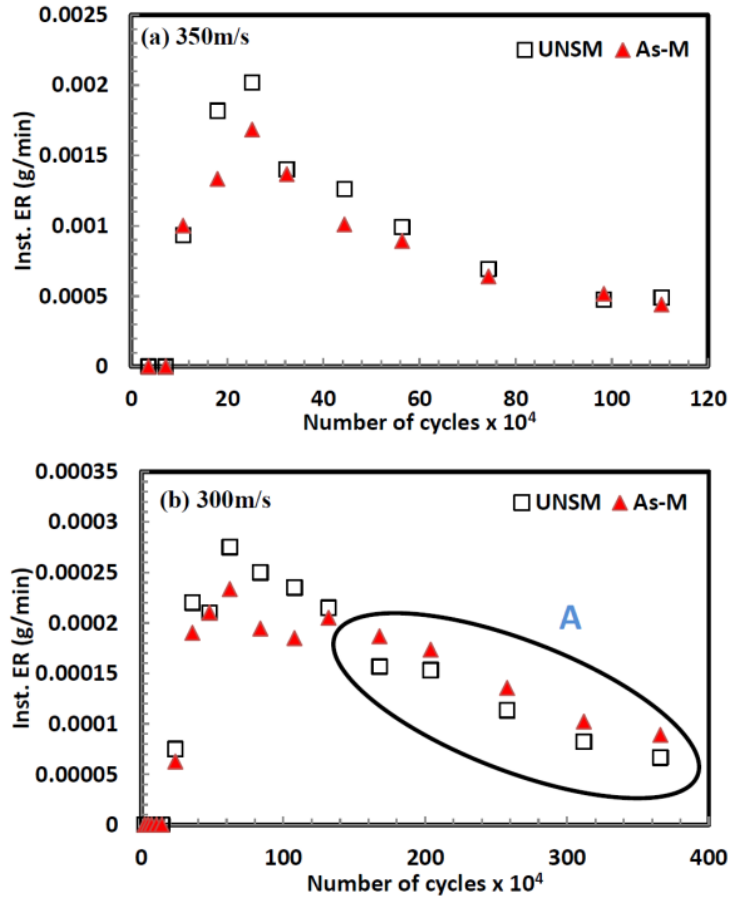

Figure 7: Inst. ER for As-M and UNSM airfoil samples at different impact speeds [9].

Based on the observed trend in Figure $7 \mathrm{~b}$ (Region A), another airfoil specimen was UNSM treated. However, in this treatment, the edge of the specimen was not treated i.e. about $0.5 \mathrm{~mm}$ from the edge was untreated. Figure 8 shows the WDE performances of the UNSM condition without edge treatment versus As-M condition at $300 \mathrm{~m} / \mathrm{s}$. It can be seen clearly that not treating the edge of the airfoil sample proves to be beneficial in mitigating the erosion damage especially at the advanced stages. Region B in Figure 8a shows that both samples had similar erosion behaviour during the early stages. This behaviour is expected because both conditions were untreated at that portion. However, after $60 \times 10^{4}$ cycles, the UNSM condition showed significant performance which confirms the hypothesis observed in Figure $7 \mathrm{~b}$ (region A). The inst. ER graph shown in Figure $8 \mathrm{~b}$ also revealed that the UNSM airfoil without edge treatment has slower erosion rates than the As-M condition. To further emphasize this point, another set of UNSM processing and WDE test was carried out in a similar fashion. Similar trends to Figure 8 were observed as well. This is due to the fact that compressive residual stresses are through the thickness of the airfoil. Typically, UNSM induces compressive residual stress up to 0.25 to $0.5 \mathrm{~mm}$ into the material. The airfoil used in this work has a tip thickness of $1.29 \mathrm{~mm}$ and was treated from both sides. Hence, it is justifiable to say that the induced compressive residual stresses are across the sample thickness. 

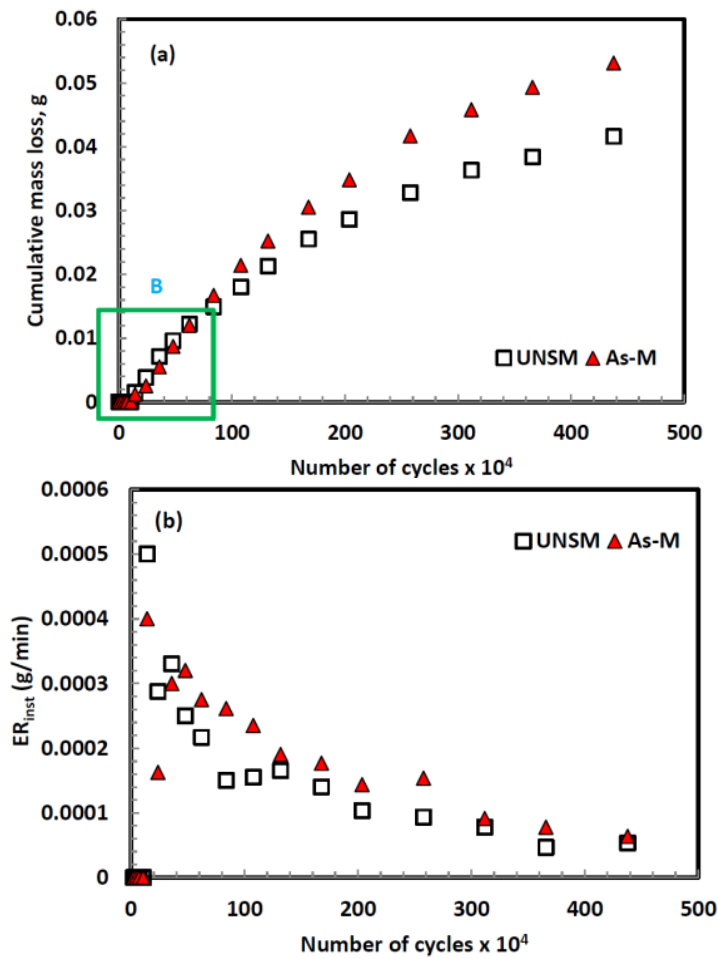

Figure 8: WDE performance of UNSM airfoil without edge treatment versus As-M at $300 \mathrm{~m} / \mathrm{s}$.

The As-M and UNSM airfoil samples were observed under the optical microscope during test interruptions. However, for this sample geometry, the images were taken at two different orientations considering the fact that the WDE tests were conducted perpendicular to the untreated and UNSM treated surfaces. Figures $8 \mathrm{a}$ and $8 \mathrm{~b}$ shows the WDE performance of the UNSM airfoil without edge treatment versus As-M airfoil tested at $300 \mathrm{~m} / \mathrm{s}$. Figure 9a shows the macrograph of the UNSM airfoil with the untreated edge, whereas Figure $9 \mathrm{~b}$ shows the erosion evolution and progression. With increase in exposure, the craters further deepen and widen due to the accumulated liquid impacts and the radial outflows. This translates to more mass loss during testing. The increase in depth with increase in exposure can be seen more clearly in this geometry than in the T-shaped flat samples. Similar to the flat specimen, increasing the impact speed showed quicker erosion initiation and greater $\mathrm{ER}_{\max }$.

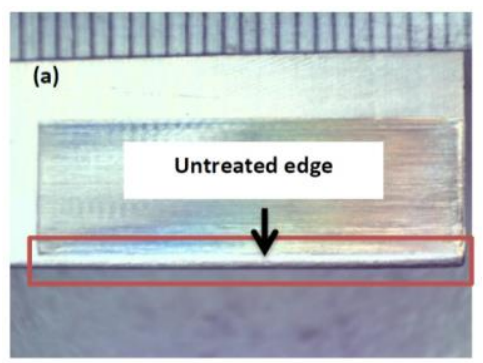

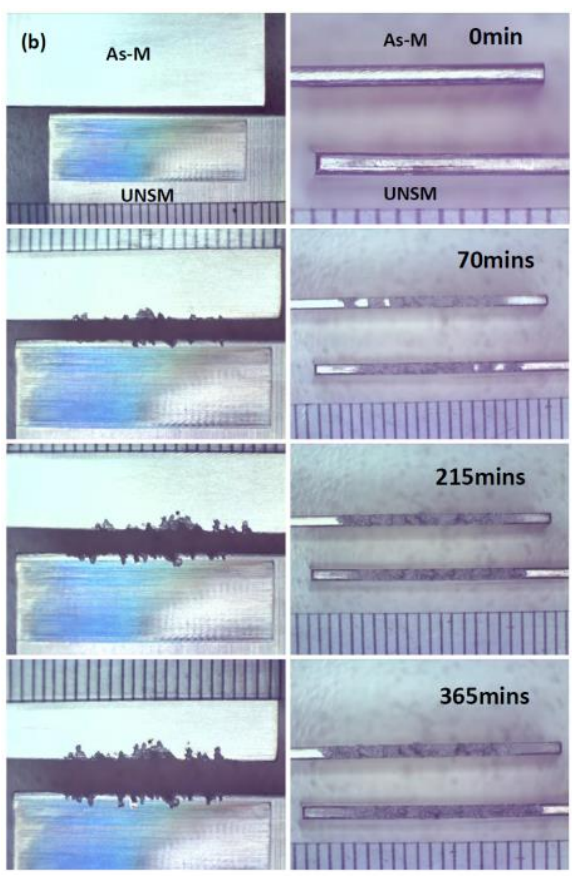

Figure 9: OM images showing (a) the untreated airfoil edge and (b) the erosion evolution and progression on As-M and UNSM (with untreated edge) airfoil samples at $300 \mathrm{~m} / \mathrm{s}$.

\section{CONCLUSIONS}

This study investigated the effect of UNSM treatment and geometry on the WDE performance of Ti-6Al-4V. The following conclusions could be drawn from this study:

- Deep levels of compressive residual stresses were induced after UNSM treatment. Also, the average grain size before and after UNSM is 20 and $12 \mu \mathrm{m}$, respectively. Hence, microhardness was increased significantly.

- Generally, increasing the impact speed showed faster erosion initiation and greater $\mathrm{ER}_{\max }$ as compared with lower speed tests.

- UNSM T-shaped flat condition showed enhanced WDE performances especially at speeds of 250 and $300 \mathrm{~m} / \mathrm{s}$ as compared with the As-M condition. This was attributed to the refined microstructure and increased microhardness. At speed of $350 \mathrm{~m} / \mathrm{s}$, the UNSM and As-M conditions showed similar WDE performance.

- UNSM airfoil had enhanced WDE performance at the later stages as compared with the As-M condition. This is due to the specimen geometry where the compressive residual stresses are through the thickness.

- This work shows that not treating the airfoil tip had beneficial effect in arresting and suppressing the erosion damage especially at advanced WDE stages.

\section{ACKNOWLEDGEMENTS}

The authors (A. K. Gujba and M. Medraj) gratefully acknowledge the financial support provided by Concordia University, Montreal, Canada through the Horizon Postdoctoral Fellowship and Natural Sciences and Engineering Research Council (NSERC) of Canada. 


\section{REFERENCES}

[1] ASTM G40-15, "Standard terminology relating to wear and erosion," ASTM Int., West Conshohocken, PA, 2015. Available online: www.astm.org.

[2] H. S. Kirols, "Water droplet erosion: Influencing parameters, representation and comparisons," Master's thesis, Concordia University, Montreal, Canada, 2015.

[3] F. G. Hammitt, and F. J. Heymann, "Liquid-erosion failures, failure analysis and prevention," ASM Handbook, ASM International, Vol. 11, 1986, pp. 163-171.

[4] M. C. Kong, D. Axinte, and W. Voice, "Aspects of material removal mechanism in plain waterjet milling on gamma titanium aluminide," J. Mater. Process. Technol., Vol. 210, No. 3, 2010, pp. 573-584.

[5] F. J. Heymann, "Erosion by liquids," Mach. Des., 1970, pp. 118-124.

[6] D. Ma, A. Mostafa, D. Kevorkov, P. Jedrzejowski, M. Pugh, and M. Medraj, "Water impingement erosion of deep-rolled Ti64," Metals, Vol. 5, No. 3, 2015, pp. 1462-1486.

[7] A. K. Gujba, L. Hackel, and M. Medraj, "Water droplet erosion performance of laser shock peened Ti-6Al-4V," Metals (Basel)., Vol. 6, No. 11, 2016, pp. 262.

[8] A. Amanov, Y. S. Pyun, and S. Sasaki, "Effects of ultrasonic nanocrystalline surface modification (UNSM) technique on the tribological behavior of sintered Cu-based alloy," Tribol. Int., Vol. 72, 2014, pp. 187-197.

[9] A. K. Gujba, Z. Ren, Y. Dong, C. Ye, and M. Medraj," Effect of ultrasonic nanocrystalline surface modification on the water droplet erosion performance of Ti-6Al-4V," Surf. Coat. Technol., Vol. 307, 2016, pp. $157-170$.

[10] A. K. Gujba, L. Hackel, D. Kevorkov, and M. Medraj, "Water droplet erosion behaviour of Ti-6Al-4V and mechanisms of material removal at the early and advanced stages. Wear, Vol. 358-359, 2016, pp. 109-122.

[11] ASTM G73-10, "Standard test method for liquid impingement erosion using rotating apparatus," ASTM Int., West Conshohocken, PA, 2010. Available online: www.astm.org.

[12] F. Heymann, "On the time dependence of the rate of erosion due to impingement or cavitation," ASTM STP 408, 1967, pp. 70-110.

[13] T. Sanada, K. Ando, T. Colonius, "A Computational Study of high-speed droplet impact," Fluid Dynamics and Materials Processing, Vol. 7, No. 4, 2011, pp. 329-340.

[14] M. B. Lesser, J. E. Field: The impact of compressible liquids. Annual Review Fluid Mechanics, Vol. 15, 1983, pp. 97-122.

[15] F. Heymann, "High speed liquid impact between a liquid drop and a solid surface," Journal of Applied Physics, Vol. 40, No. 13, 1969, pp. 5113-5122.

[16] M. Ahmad, M. Casey, and N. Sürken, "Experimental assessment of droplet impact erosion resistance of steam turbine blade materials," Wear, Vol. 267, No. 9-10, 2009, pp. 1605-1618.

[17] A. K. Gujba, and M. Medraj, "Laser peening process and its impact on materials properties in comparison with shot peening and ultrasonic impact peening," Mat., Vol. 7, No. 12, 2014, pp. 7925-7974. 